\title{
A Simple Model of Gulf Stream Thermal Structure with Application to the Analysis of Moored Measurements in the Presence of Mooring Motion
}

\author{
ROSS HENDRY \\ Physical and Chemical Sciences, Department of Fisheries and Oceans, Bedford Institute \\ of Oceanography, Dartmouth, Nova Scotia, Canada
}

(Manuscript received 1 July 1987, in final form 14 October 1987)

\begin{abstract}
Current meters on long moorings placed in the Gulf Stream near $59^{\circ} \mathrm{W}$ during 1983-84 experienced timevarying vertical displacements of many hundreds of meters. As an aid to interpreting the resulting velocity and temperature signals, a parametric model of Gulf Stream thermal structure was developed on the basis of a detailed survey of the area. The model translates moored measurements of temperature and pressure to a vertical and cross-stream position in a coordinate system associated with the instantaneous Gulf Stream. Temperature as a function of cross-stream position and pressure, as measured in the survey, is reproduced to within about $0.3^{\circ} \mathrm{C}$ root-mean-square residual for pressures between 200 and $1500 \mathrm{dbar}$ and temperatures between $4.5^{\circ}$ and $19^{\circ} \mathrm{C}$ using a simple analytical model with a limited number of empirically determined parameters. The model spans a cross-stream range of approximately $150 \mathrm{~km}$. This construct provides a framework for analyzing the measured data and also provides a realistic local representation of the Gulf Stream.
\end{abstract}

\section{Introduction}

Ocean measurement technology has recently advanced to the point of allowing long-term direct measurements of the relatively strong currents in the Gulf Stream from fixed moorings supported by subsurface flotation, but technical constraints and economic factors led to the design of moorings which undergo considerable horizontal and vertical excursions in response to the associated horizontal drag forces. These forces vary in time with the currents, and the moored sensors sample the water column at varying levels depending on the very phenomenon the sensors are meant to measure.

Horizontal excursions of a few kilometers and vertical excursions of a few hundred meters are typical values of the displacements encountered by a $500-\mathrm{m}$ level sensor at the top of a $5000 \mathrm{~m}$ long intermediate mooring in a Gulf Stream setting, involving speeds in excess of $1 \mathrm{~m} \mathrm{~s}^{-1}$ at the $500-\mathrm{m}$ level. The horizontal excursions are not generally important since the features being measured have horizontal scales of many kilometers and the rate of horizontal motion of the sensors is small compared to the ambient currents. Vertical excursions associated with these horizontal movements are more problematic because current and temperature can vary significantly in the vertical in the Gulf Stream on the scales of the expected vertical dis-

Corresponding author address: Dr. Ross Hendry, Physical and Chemical Sciences, Department of Fisheries and Oceans, Bedford Institute of Oceanography, Dartmouth, N.S., Canada B2Y 4A2. placements, so the moored sensors measure a mixture of temporal and spatial variability. If the vertical displacements are small enough and if information is available about vertical gradients, a local interpolation/ extrapolation scheme may be successful in correcting the resulting time series to a fixed vertical level for conventional time series analysis. This procedure is especially effective if sensors are closely spaced in the vertical, but it is not always practical. Typically, only a limited number of sensors are available, and scientific considerations may dictate that the water column be sampled at widely spaced intervals.

This paper discusses an approach to the problem of analyzing moored data from the Gulf Stream or other strong, structured currents in the presence of mooring motions which are too large for a local technique to encompass. A simple parametric model of the temperature field associated with the Gulf Stream is constructed on the basis of a detailed survey of the study area, with temperature being specified as a function of pressure and distance normal to the axis of the instantaneous stream. Pressure and temperature measured by a moored sensor can then be transferred to a streambased coordinate system to provide a perspective for further analysis. The parametric model provides an economical and reasonably realistic fit to the field observations, and the approach, though obviously idealized, shows some promise.

\section{The moored experiment}

Five intermediate moorings were placed in the Gulf Stream by the Atlantic Oceanographic Laboratory 
(AOL) of the Bedford Institute of Oceanography (BIO) in May 1983 in an array centered at $39^{\circ} 30 \mathrm{~N}$ and $59^{\circ} \mathrm{W}$ as part of a study of the local structure of the mean and time-varying flows in the stream. Other moorings had been set in the area by the Woods Hole Oceanographic Institution (WHOI) in a related effort with wider geographical coverage (Hogg et al., 1986). Figure 1 shows the locations of the relevant moorings and representative estimates of the mean location and geographic limits of the Gulf Stream surface landward edge obtained from 1 yr of observations (Auer, 1983). Figure 2 shows a schematic of the AOL mooring design adopted for the Gulf Stream study. Each mooring carried four Aanderaa RCM-5 current meters at nominal depths of $500,900,1400$ and $4000 \mathrm{~m}$ in approximately 5150-m water depth. The moorings were supported by an upper primary buoyancy element consisting of a streamlined shell enclosing a number of hollow glass spheres, and by backup buoyancy in the form of additional glass spheres in unstreamlined capsules distributed along the mooring. The allowable tension in a mooring was constrained to give less than a specified fraction of the breaking strain of the weakest element in the mooring, and buoyancy was to be provided to achieve the stiffest possible mooring and minimum mooring motion consistent with this criterion. An extreme current profile was used to model the maximum

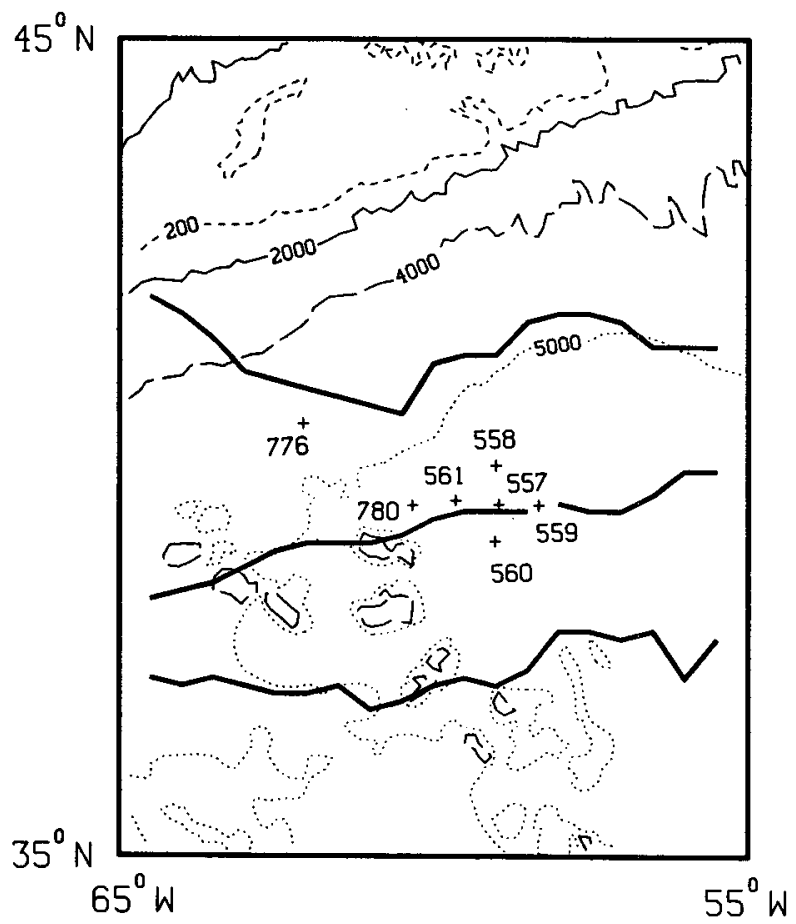

Fig. 1. Chart of the study area showing the location of moorings comprising the AOL Gulf Stream Array (moorings 557-561) and WHOI moorings 776 and 780 . Mean, maximum and minimum limits for the landward surface edge of the Gulf Stream are included in the figure. Selected bathymetric contours are labeled in meters.

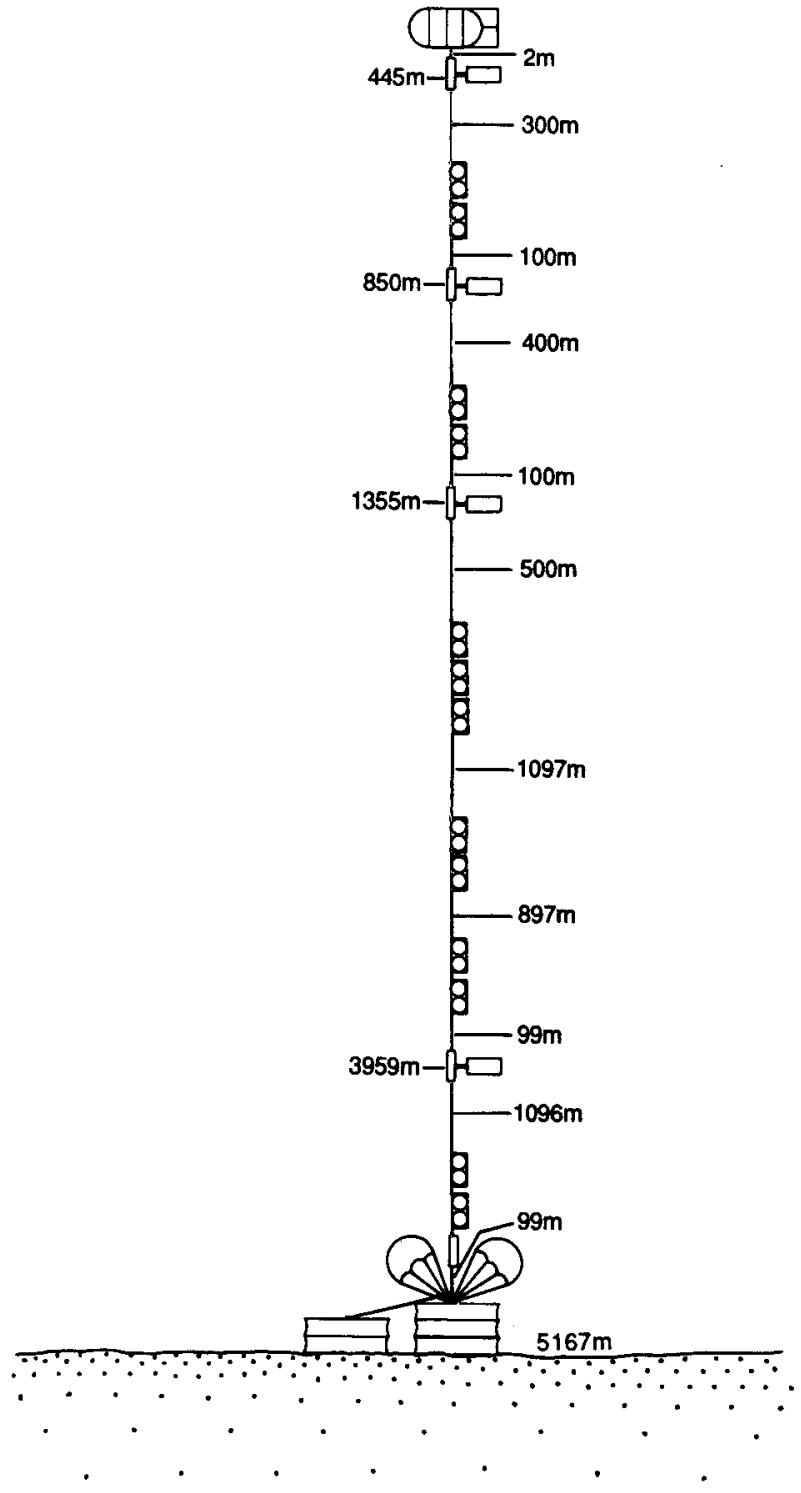

FIG. 2 Schematic of the mooring design adopted for the AOL Gulf Stream study.

likely displacement of the various packages on the mooring to guard against overpressuring and to evaluate the mooring from the point of view of the scientific goals of the study. The extreme design current profile included a deep flow of $0.5 \mathrm{~m} \mathrm{~s}^{-1}$ through the lower 3 $\mathrm{km}$ of the water column based on earlier Gulf Stream measurements near $55^{\circ} \mathrm{W}$ (Hendry, 1982) which contributed significantly to the total drag. The design study for the Gulf Stream moorings indicated that the nominal $500-\mathrm{m}$ level instrument might be displaced as much as $500 \mathrm{~m}$ in the vertical. It was felt that the scientific goals of the study could be achieved even with occasional excursions of this order.

Table 1 gives a summary of the extremes of pressure and speed from daily averages of hourly measurements 
TABLE 1. Summary of the statistics of vertical displacements and maximum speeds encountered by mooring $557\left(39^{\circ} 30.2 \mathrm{~N}, 58^{\circ} 57.4^{\prime} \mathrm{W}\right.$, $5167 \mathrm{~m}$ water depth) between May 1983 and April 1984. The table includes the minimum, mean and maximum daily average pressure encountered by each of the four current meters on the mooring; the 99th percentile and maximum vertical displacement of each current meter in pressure units; the standard deviation of pressure from the mean; and the maximum speed of the daily averaged flow and the corresponding pressure for each current meter. The number of days of measurements for each record are also givert, with parenthetical values added for velocity records which had fewer days of valid readings in several cases.

\begin{tabular}{|c|c|c|c|c|c|c|c|c|}
\hline \multirow[b]{2}{*}{ No. of days } & \multicolumn{3}{|c|}{ Pressure } & \multicolumn{2}{|c|}{ Excursion } & \multirow[b]{2}{*}{$\begin{array}{l}\text { Std. dev. } \\
\text { (dbar) }\end{array}$} & \multicolumn{2}{|c|}{ Maximum speed } \\
\hline & $\underset{\text { (dbar) }}{\text { Minimum }}$ & $\begin{array}{l}\text { Mean } \\
\text { (dbar) }\end{array}$ & $\underset{(\text { dbar })}{\text { Maximum }}$ & $\begin{array}{l}99 \% \\
\text { (dbar) }\end{array}$ & $\begin{array}{l}\text { Maximum } \\
\text { (dbar) }\end{array}$ & & $\begin{array}{l}\text { Speed } \\
\left(\mathrm{m} \mathrm{s}^{-1}\right)\end{array}$ & $\begin{array}{l}\text { Pressure } \\
\text { (dbar) }\end{array}$ \\
\hline $358(325)$ & 336 & 506 & 1382 & 654 & 1046 & 162 & 0.94 & 615 \\
\hline 358 & 749 & 920 & 1792 & 641 & 1043 & 160 & 0.41 & 1459 \\
\hline 358 & 1268 & 1430 & 2264 & 622 & 996 & 155 & 0.41 & 1788 \\
\hline $358(277)$ & 3968 & 4029 & 4240 & 272 & 498 & 67 & 0.37 & 4234 \\
\hline
\end{tabular}

at the central mooring 557 for the first of two successive year-long deployments. The observed maximum upper-level flows were comparable to those assumed in the design profile, while the observed maximum deep flows were about $15 \%$ less than assumed. The observed vertical excursions were also comparable with the model predictions except during one extreme event lasting several days which gave rise to exceptional vertical displacements, in excess of $1000 \mathrm{~m}$ for the 500 $\mathrm{m}$ level current meter. These data are now being used to improve the calibration of our mooring motion model. It appears that the buoyancy actually provided by the primary flotation package was only about $77 \%$ of the nominal $4450 \mathrm{~N}$ specified in the design because of an operational mix-up, and better performance would have been achieved with the original design. The WHOI intermediate mooring 780 of similar length but slightly different design deployed nearby used more than twice as much total buoyancy and experienced only about $65 \%$ as much root-mean-square vertical motion at the uppermost level in the presence of slightly weaker currents (Levy and Tarbell, 1986).

Figure 3 shows a composite hodograph of daily averages of temperature and pressure from the five AOL Gulf Stream moorings at the uppermost three measurement levels between May 1983 and April 1984. The warmest temperatures at a given pressure represent conditions on the warm side of the Gulf Stream approaching the Sargasso Sea, and the coldest temperatures at a given pressure level represent conditions on the cold side of the stream approaching the slope water. The vertical excursions of the current meters in reaction to changing currents lead to a mixed space and time sampling of the current and temperature fields and create a problem in interpreting the statistics of measurements from an individual record. The approach explored here is to investigate the possibility that the measured pressure and temperature signals could be transformed to a new coordinate system embedded in the instantaneous Gulf Stream.

\section{Modeling the thermal structure of the Gulf Stream}

The moored array study of the Gulf Stream was complemented by a sequence of five hydrographic cruises during the 2 years of moored measurements. In particular, cruise 83-029 of CSS Dawson surveyed the Gulf Stream near the moored array during September 1983 by means of 35 conductivity-temperature-pressure (CTP) casts within an area roughly 350

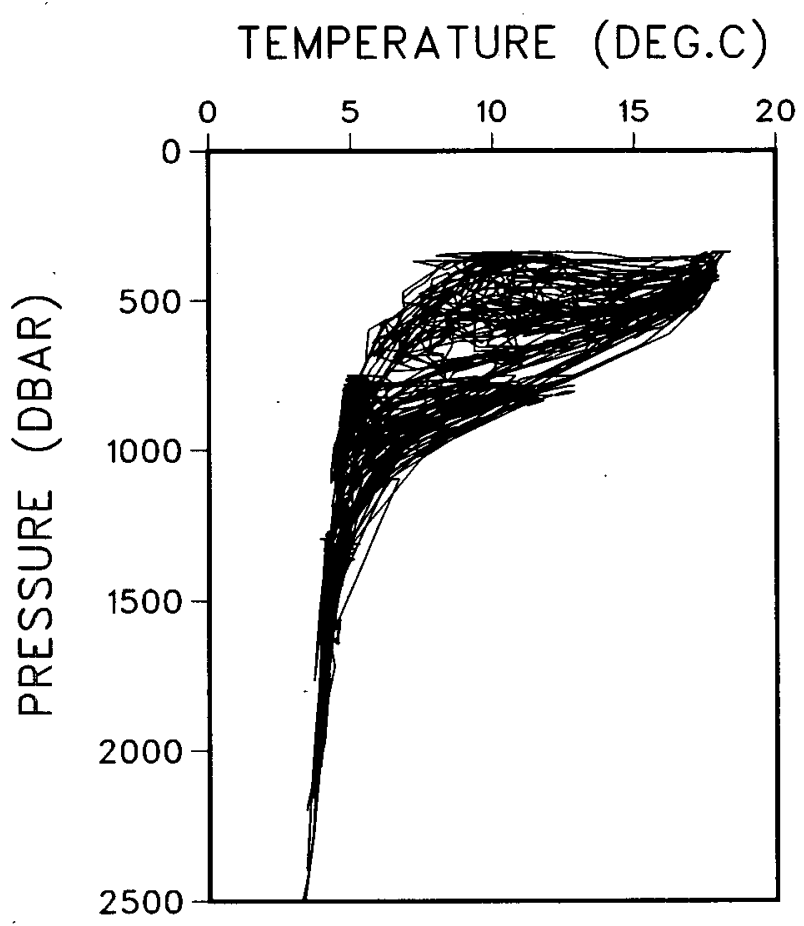

FiG. 3. Hodograph of daily averages of pressure and temperature from 14 individual current meters at three nominal vertical levels $(500,900$, and $1400 \mathrm{~m})$ between May 1983 and April 1984, giving an overview of the range of temperatures associated with the Gulf Stream at various pressures and showing the vertical displacements experienced by the current meters. 


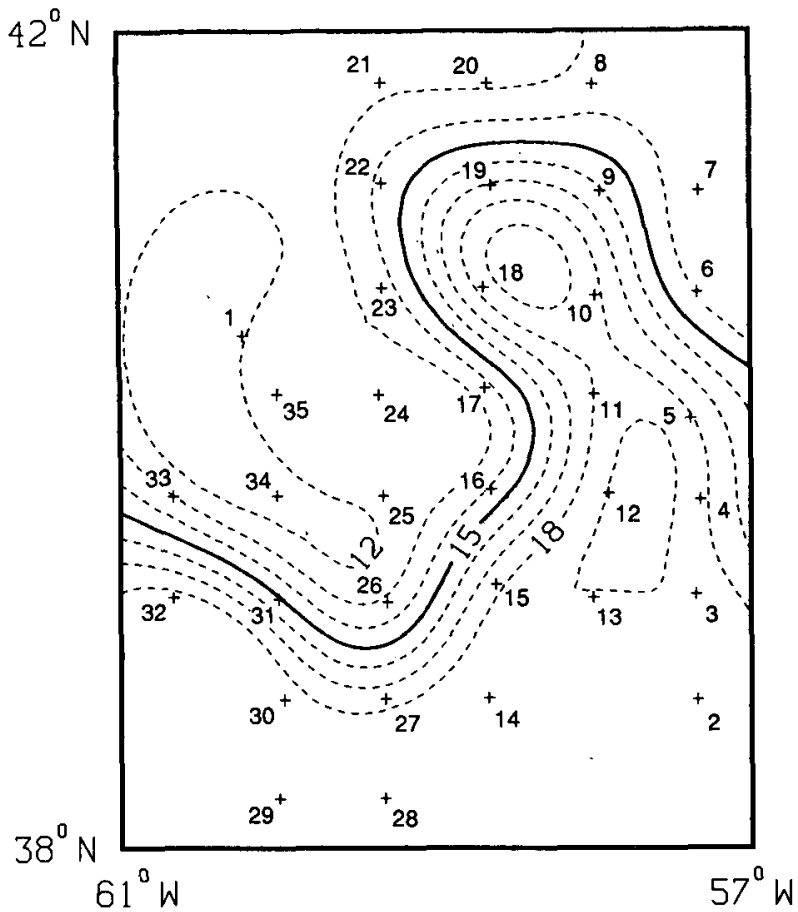

FIG. 4. Station plan and contours of the temperature at $200 \mathrm{dbar}$ from a hydrographic survey carried out by CSS Dawson in September 1983. Station numbers posted on the plan are referred to in the text. The $15^{\circ} \mathrm{C}$ isotherm emphasized in the figure was used as an axis for the Gulf Stream and the minimum normal distance from each station to this axis was used as a cross-stream coordinate.

$\mathrm{km}$ on a side. Figure 4 shows the resulting station positions and an analysis of temperature at $200 \mathrm{dbar}^{1}$ pressure. The $15^{\circ} \mathrm{C}$ isotherm at $200 \mathrm{dbar}$ emphasized in the figure is a conventional marker for the inshore edge of the Gulf Stream. The hydrographic survey was designed to give measurements extending across the Gulf Stream, including stations in both the warm and cold waters bounding the Stream. Figure 5 shows the family of temperature profiles measured at the 35 stations in the survey for pressures less than $2500 \mathrm{dbar}$. The figure excludes waters warmer than $20^{\circ} \mathrm{C}$ in the near-surface, seasonally warmed layer found well above the shallowest sensors on the Gulf Stream moorings. The range of temperatures encountered in the 2-week CTP survey is comparable to the range of temperatures sampled by the moored sensors at corresponding pressures during the year-long deployment as shown in Fig. 3 , and both datasets include more or less the full range of temperatures characteristic of a Gulf Stream cross section.

The family of temperature profiles in Fig. 5 shows a regular progression from the warm side of the stream,

\footnotetext{
${ }^{1} 1$ decibar (dbar) $=10^{4} \mathrm{~Pa}$. The depth of a column of seawater expressed in meters is numerically nearly equal to the pressure at the base of the column expressed in decibars.
}

where the maximum vertical temperature gradient is found near $800 \mathrm{dbar}$, to the cold side of the stream, where the permanent thermocline shallows to near 200 dbar. An attempt was made to quantify the large-scale cross-stream variations in temperature by fitting analytical curves to the measured temperature profiles, specifically relating temperature to pressure through the relation

$$
T(p)=\mathrm{A} \tanh [\mathrm{B}(\mathrm{C}-p)]+\mathrm{D},
$$

where $T(p)$ is the temperature at pressure $p, \tanh (x)$ is the hyperbolic tangent function with argument $x$, and $\mathrm{A}, \mathrm{B}, \mathrm{C}$ and $\mathrm{D}$ are free parameters. The negative gradient of temperature with respect to pressure from this expression is

$$
-d T / d p=\mathrm{AB} \operatorname{sech}^{2}[\mathrm{~B}(\mathrm{C}-p)]
$$

where $\operatorname{sech}(x)$ is the hyperbolic secant function with argument $x$. Expression (2) achieves its maximum value of $\mathrm{AB}$ (for $\mathrm{AB}>0$ ) at $p=C$, and parameter $\mathrm{C}$ is identified with the pressure of maximum vertical temperature gradient, which will be loosely referred to as the thermocline pressure. Similarly, parameter D is identified with the temperature at this thermocline pressure. Parameters A and B characterize the temperature step across the thermocline and the inverse of the vertical scale of the thermocline, respectively.

This hyperbolic tangent function representation also

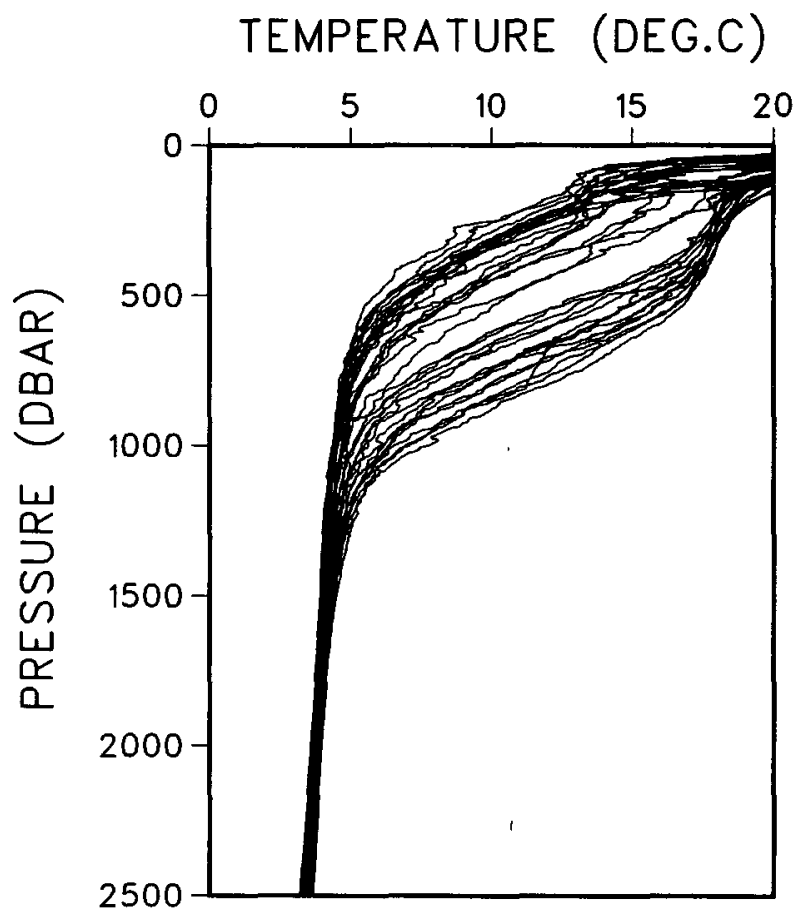

Fig. 5. Temperature profiles from 35 CTP casts from CSS Dawson cruise $83-029$ in the range 0 to 2500 dbar showing the variety of profile shapes encountered on a Gulf Stream cross section. The figure excludes temperatures warmer than $20^{\circ} \mathrm{C}$ in the seasonally warmed surface layer. 


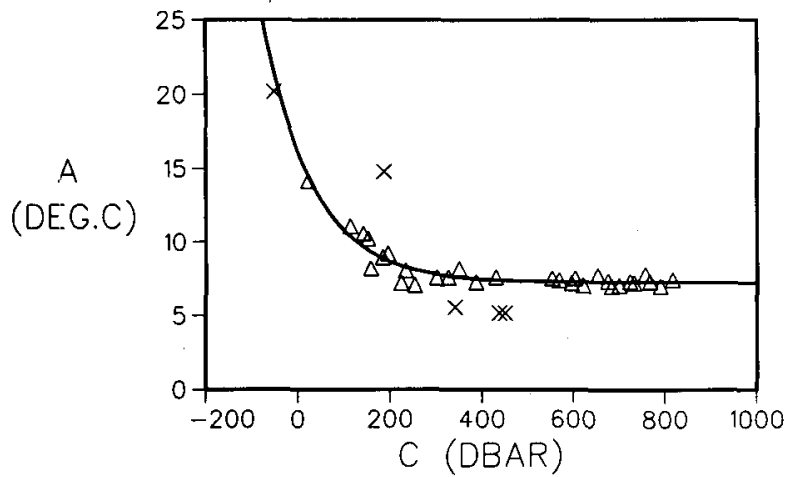

FIG. 6a. Scatter plot of parameter A (thermocline temperature step) versus parameter $C$ (thermocline pressure) derived from curve fits of 35 temperature profiles from CSS Dawson cruise 83-029 as discussed in the text and in appendix A: The solid curve is a leastsquares fit using an exponential function, excluding the five values denoted by the symbol " $X$ ".

arose in a recent paper of Hogg (1986) which discussed a temperature extrapolation scheme for moored measurements based on a quadratic fit of vertical temperature gradient to temperature of the form

$$
-d T / d p=\mathrm{a}_{0}+\mathrm{a}_{1} T+\mathrm{a}_{2} T^{2} .
$$

This is equivalent to

$$
-d T / d p=\mathrm{B}\left(\mathrm{A}^{2}-\mathrm{D}^{2}\right) / \mathrm{A}+(2 \mathrm{BD} / \mathrm{A}) T-(\mathrm{B} / \mathrm{A}) T^{2}
$$

in terms of (1) and (2) above. Appendix B expands on the relationship between the present model and the work of Hogg (1986).

As detailed in appendix A, Eq. (1) was fit to the 35 temperature profiles from the Dawson cruise in the pressure range 200 to $1500 \mathrm{dbar}$ and the temperature range $4.5^{\circ}$ to $19^{\circ} \mathrm{C}$. These limits exclude the seasonal layer and generally delimit the main thermocline regime. The best-fitting parameters $\mathrm{A}, \mathrm{B}, \mathrm{C}$ and $\mathrm{D}$ were determined for each profile using temperature readings sampled at $50 \mathrm{dbar}$ intervals. The overall rms temperature residual after the fits were subtracted from the

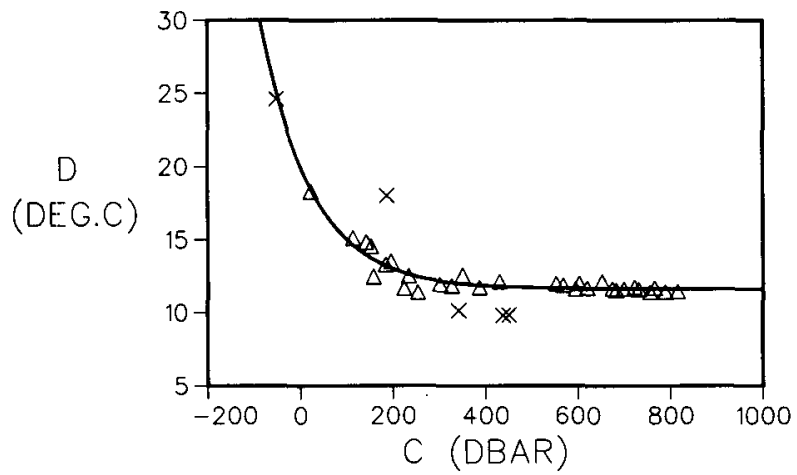

FiG. 6c. As in Fig. 6a except for parameter D (thermocline temperature) versus parameter $C$. The fitted curve is an exponential of the same form as for $A$ versus $C$ in Fig. $6 a$.

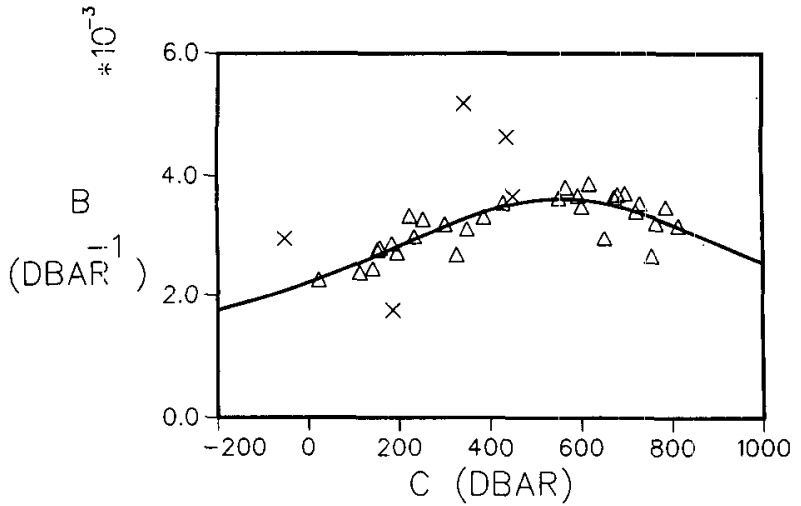

FIG. 6b. As in Fig. 6a except for parameter B (the inverse of the vertical scale of the thermocline) versus parameter $C$. The fitted curve is a hyperbolic secant function.

measured profiles was $0.16^{\circ} \mathrm{C}$, with the maximum for any station being $0.35^{\circ} \mathrm{C}$. The residuals include the contribution of small-scale temperature variability; nonstationarity of the profiles in the vertical due to ship drift, temporal change during a profile, or transient vertical structures; and the intrinsic limitations of the assumed functional form for the large-scale structure. A clear example of nonstationary vertical structure appears in one profile in Fig. 5, from station 28 on the warm side of the Gulf Stream. This station shows a linear transition region about 200 dbar in extent centered near $750 \mathrm{dbar}$ and $11.5^{\circ} \mathrm{C}$ which connects two distinct temperature versus pressure regimes, and it gave rise to the maximum rms residual quoted above. In general, the four-parameter fit is reasonably successful in capturing most of the variance associated with the larger vertical scales.

If the four parameters in the hyperbolic tangent fits could be interrelated so that the model depended on only a single free parameter, a paired measurement of pressure and temperature would uniquely define a temperature profile, and the model could be used to

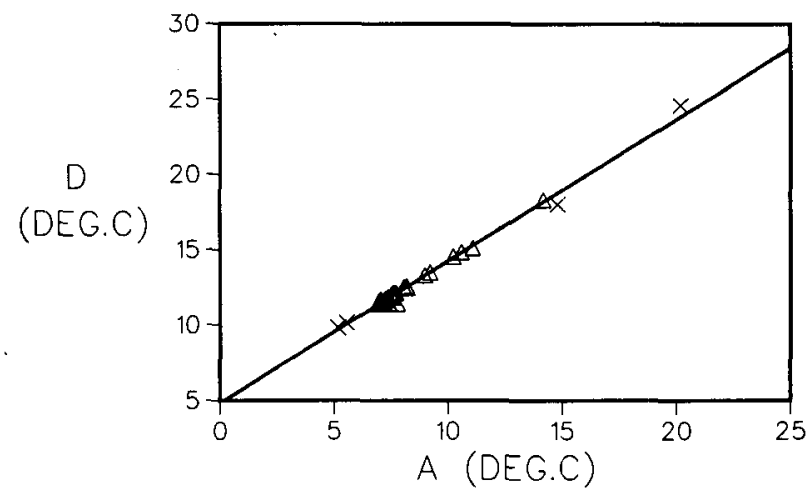

FIG. 5d. Scatter plot of parameter D versus parameter A with a best-fitting linear regression, as in Fig. $6 \mathrm{a}$. This linear fit and the fit of $A$ versus $C$ give a composite model for $D$ versus $C$ as an alternative to the direct fit in Fig. 6c. 


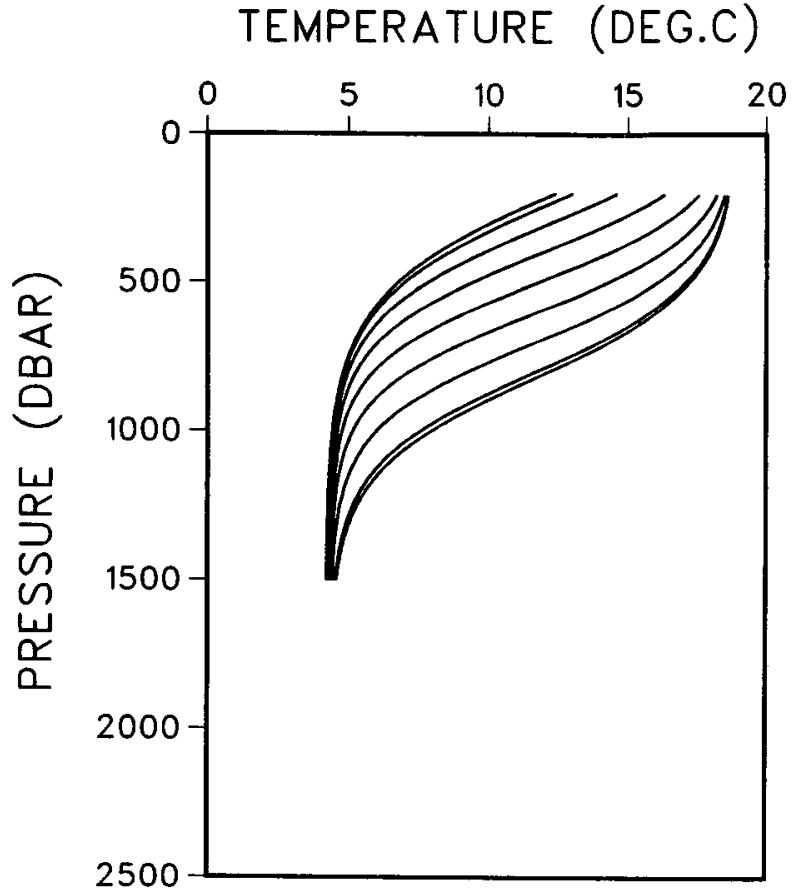

FIG. 7. Representatives of a one-parameter family of model curves giving temperature as a function of pressure for different choices of thermocline pressure between 120 dbar (coldest profile) and $820 \mathrm{dbar}$ (warmest profile). Intermediate profiles show examples with thermocline pressures a multiple of $100 \mathrm{dbar}$ between 200 and $800 \mathrm{dbar}$.

estimate the temperature at a standard level using measurements from a single current meter. After various exploratory analyses, the thermocline pressure $\mathrm{C}$ was used to parameterize the profiles. The fitted values of $C$ in the four-parameter fits varied from -51 to 815 dbar. Values of $\mathrm{C}$ less than 200 dbar produce a virtual thermocline pressure less than the minimum pressure sampled by the data used in the fit, and the fitted profiles within the physically relevant pressure range are of an exponential nature with no intermediate inflection point and with maximum vertical gradient of temperature at the 200-dbar level. Figures $6 a-c$ show scatter plots of the freely fitted parameters A, B and D against the parameter $C$ obtained in the same fits. A scatter plot of parameter $D$ versus parameter $A$ is given in Fig. 6d. Figures 6a-d also show curve fits using simple analytical relations suggested by the observed correlations among the parameters. Five of the 35 stations were judged anomalous and were excluded from the calculations of these curve fits, as indicated in the scatter plots. Figure 7 shows examples of the one-parameter family of temperature profiles resulting from the composite model combining (1) and the curve fits relating parameters A, B and D to thermocline pressure. As discussed in appendix $A$, this family is defined by nine fixed empirical parameters in addition to the free parameter specifying thermocline pressure which ranges continuously between 120 and $820 \mathrm{dbar}$.

Having collapsed the model onto a single parameter, the best-fitting value of thermocline pressure subject to the added constraints of the composite model was recomputed for each of the 35 original stations. The resulting new set of values for parameter $\mathrm{C}$ ranged from 100 to $804 \mathrm{dbar}$, and the overall rms temperature residual from the new fits was $0.31^{\circ} \mathrm{C}$. If the five outlier stations in the parameter versus parameter fits were excluded, the overall $\mathrm{rms}$ temperature residual dropped to $0.21^{\circ} \mathrm{C}$. As mentioned above, the four-parameter fits left an rms residual of about $0.16^{\circ} \mathrm{C}$ for either grouping.

A final step in the construction of a thermal model of the Gulf Stream was to associate a cross-stream po-

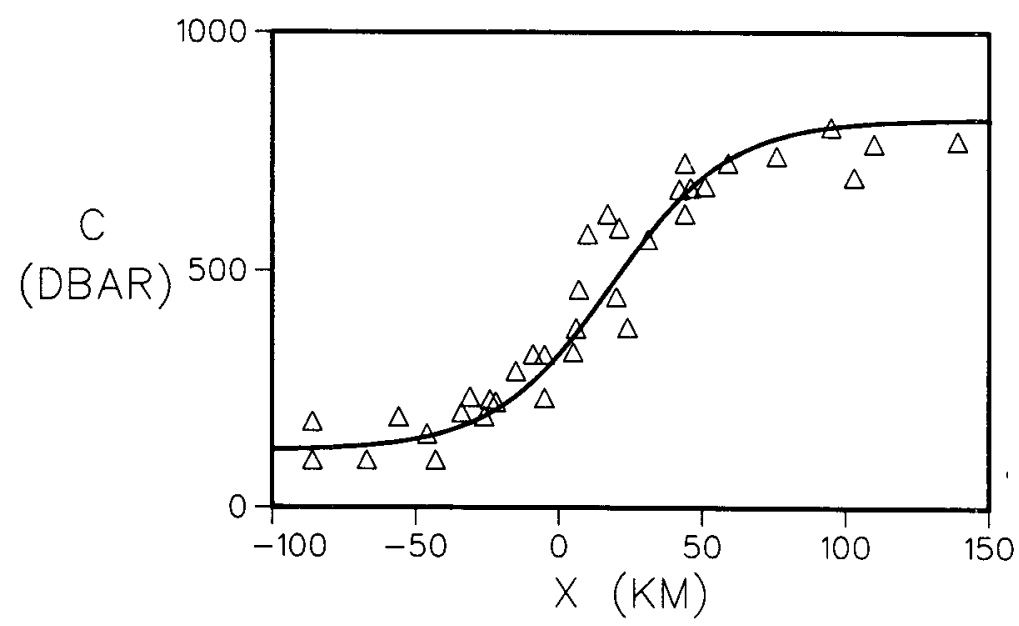

FIG. 8. Scatter plot of parameter $\mathrm{C}$ (thermocline pressure) against the normal distance to the $15^{\circ} \mathrm{C}$ isotherm at 200 dbar for 35 CTP stations from Dawson cruise 83-029. Details are discussed in the text and in appendix A. The solid curve is a hyperbolic tangent function fit to the scattered points as discussed in appendix $A$. 


\section{TEMPERATURE (DEG.C)}

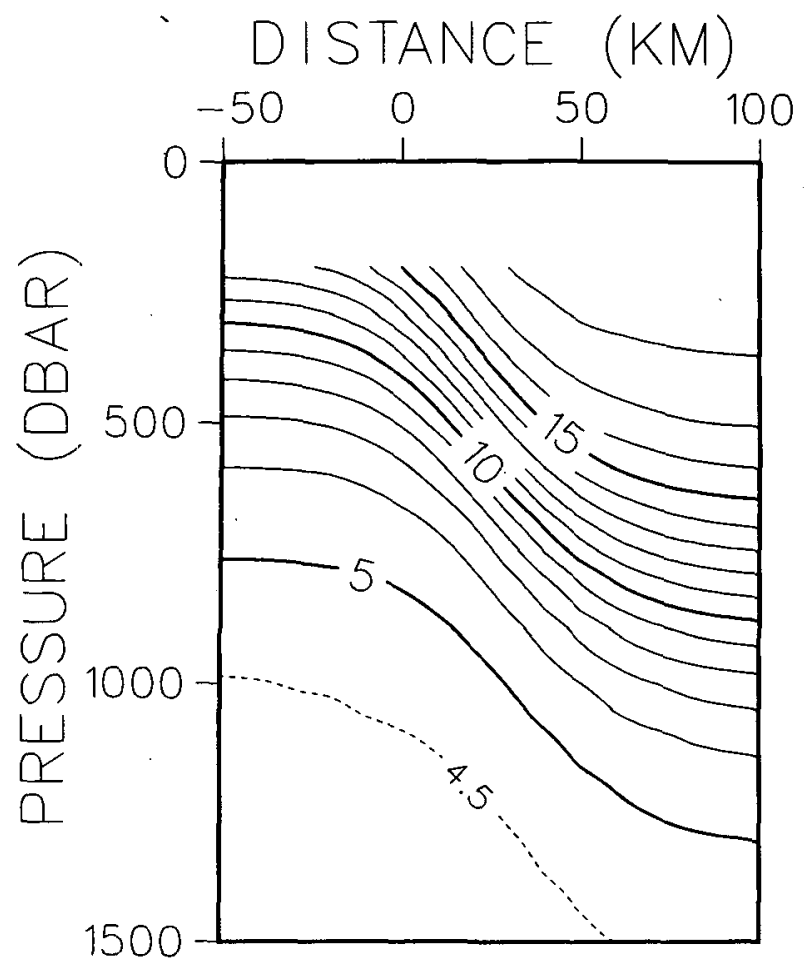

FIG. 9a. Model temperature (degrees Celsius) versus pressure and cross-stream coordinate in the ranges 200-1500 dbar and -50 to $100 \mathrm{~km}$, respectively. The intersection of the $15^{\circ} \mathrm{C}$ isotherm with the $200 \mathrm{dbar}$ surface defines the origin of the cross-stream coordinate system.

sition with a given temperature profile and associated thermocline pressure. The cross-stream position at which the $15^{\circ} \mathrm{C}$ isotherm shallows to 200 dbar defines a convenient origin for a stream-based coordinate system, and each station in the Dawson CTP survey was assigned a cross-stream coordinate equal to the minimurn normal distance from the station to this axis. The distances were determined graphically from Fig. 4 and were reckoned positive for stations on the seaward side of the axis and negative for stations on its landward side. Figure 8 shows a scatter plot of fitted thermocline pressure against cross-stream distance for all 35 stations and a curve fit giving thermocline pressure as a function of cross-stream position using a hyperbolic tangent function governed by four additional parameters. The analytical fit leaves a residual of approximately $66 \mathrm{dbar}$ in thermocline pressure. The details of this calculation are also given in appendix A.

\section{Application of the parametric model}

The model developed above reduces a substantial body of Gulf Stream temperature measurements to 13
-DT/DP (DEG.C/1000DBAR)

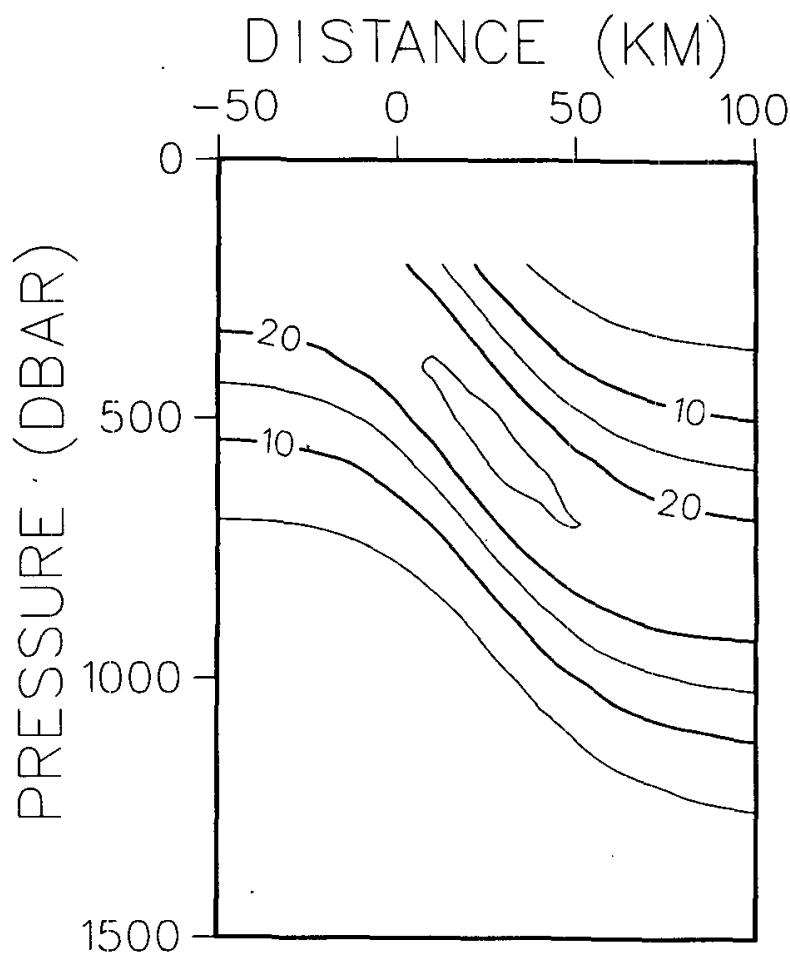

FIG. 9b. Model output of the negative gradient of temperature with respect to pressure $\left({ }^{\circ} \mathrm{C}\right.$ per $\left.1000 \mathrm{dbar}\right)$ as a function of pressure and cross-stream coordinate as in Fig. 9a.

parameters and is obviously an idealization, but being based on actual measurements, it should faithfully reproduce the larger-scale structure of the real phenomenon. Figures 9a-d illustrate the results. Figure 9a shows a contour plot of model temperature as a function of pressure from 200 to 1500 dbar and cross-stream coordiriate from -50 to $100 \mathrm{~km}$. Figures $9 \mathrm{~b}$ and c show contours of vertical and horizontal temperature gradients derived by analytically differentiating the model temperature. The cross-stream horizontal temperature gradient is related to an associated downstream geostrophic shear through the thermal wind relation. Figure $9 \mathrm{~d}$ shows contours of geostrophic flow calculated by integrating the model horizontal temperature gradient in the vertical and choosing 1500 dbar as a reference level of vanishing flow. The calculation assumes a constant effective thermal expansion of seawater of $-0.12 \mathrm{~kg} \mathrm{~m}^{-3}{ }^{\circ} \mathrm{C}^{-1}$ which includes a salinity contribution based on a nominal temperature-salinity correlation. The resulting flow field has a maximum speed of just over $1.3 \mathrm{~m} \mathrm{~s}^{-1}$ near $x=25 \mathrm{~km}$ at the $200 \mathrm{dbar}$ level. The integration was done numerically, but a closed-form expression does exist for constant thermal expansion.

As a prototype application of the model, Fig. 10 shows the measured pressure and temperature time se- 


\section{DT/DX (DEG.C/1000KM)}

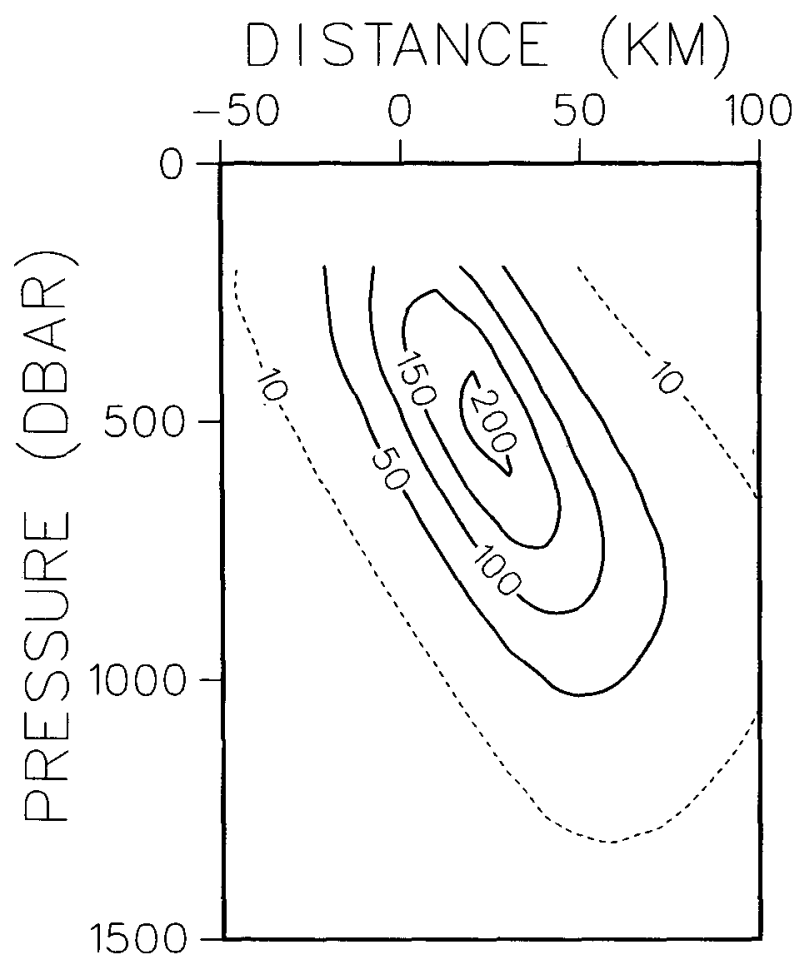

FIG. 9c. Model output of cross-stream horizontal temperature gradient $\left({ }^{\circ} \mathrm{C}\right.$ per $\left.1000 \mathrm{~km}\right)$ as in Fig. $9 \mathrm{a}$.

ries from the nominal $500-\mathrm{m}$ level at central mooring 557 and the associated time series of 200-dbar temperature and cross-stream coordinate derived from the model. These fields are calculated iteratively using Newton's method to invert the model. Of the 358 pairs of daily averaged pressure and temperature readings, four pairs had temperatures colder than the minimum model temperature for the measured pressure reading and six showed temperatures warmer than the model maximum for their pressure. These cases show as gaps in the model-derived curves in Fig. 10. The mean crossstream coordinate for the remaining 348 days was approximately $32 \mathrm{~km}$. The 200-dbar temperature suggests that the Gulf Stream shifted somewhat to the north during the later part of this measurement period, placing the mooring on the warm side of the Gulf Stream in contrast to midrecord conditions when the Stream appears to fluctuate about the position of the mooring.

An event of approximately 3-days duration in midApril 1984 gave rise to the maximum vertical excursion of the uppermost current meter on mooring 557 and appears as an anomaly in the derived time series. The 1382-dbar maximum pressure encountered was accompanied by a temperature reading of $4.42^{\circ} \mathrm{C}$, giving a computed thermocline pressure of $378 \mathrm{dbar}$ and a cross-stream coordinate of about $2 \mathrm{~km}$ in contrast to values near $750 \mathrm{dbar}$ and $60 \mathrm{~km}$, respectively, a few

\section{RELATIVE VELOCITY}

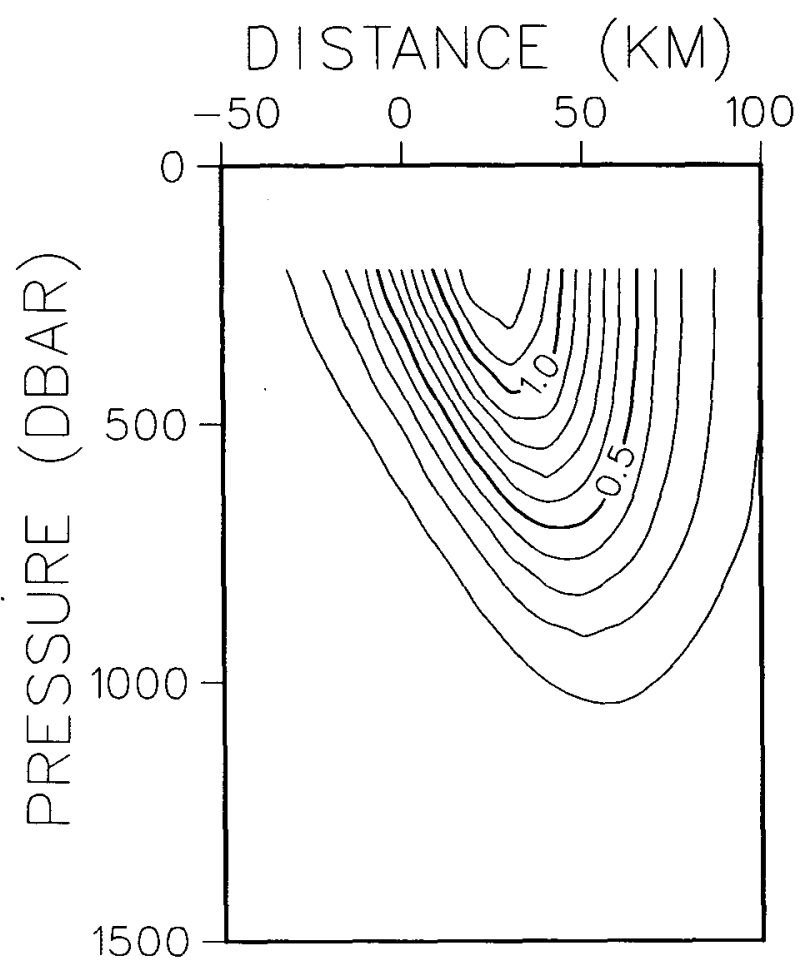

FIG. 9d. Geostrophic downstream velocity component (meters per second) relative to $1500 \mathrm{dbar}$ in the range 200 to $1500 \mathrm{dbar}$ obtained by integrating the cross-stream horizontal temperature gradient with respect to pressure using the thermal wind relationship. The calculation includes a realistic constant value of the effective thermal expansion of seawater with a correction for the effects of salinity from a nominal temperature-salinity correlation. The flow attains a maximum value of just over $1.3 \mathrm{~m} \mathrm{~s}^{-1}$ near $x=25 \mathrm{~km}$ at $200 \mathrm{dbar}$. The areal integral of this flow field between 1500 and $200 \mathrm{dbar}$ and -50 to $100 \mathrm{~km}$ gives a model volume transport of approximately 41 $\times 10^{6} \mathrm{~m}^{3} \mathrm{~s}^{-1}$, increasing to $58 \times 10^{6} \mathrm{~m}^{3} \mathrm{~s}^{-1}$ if the $200 \mathrm{dbar}$ flow is assumed to represent the flow at shallower levels and the integration is extended to the surface.

days on either side of the event. Figure 11 shows a contour plot of the sensitivity of the model thermocline pressure to a temperature change of $0.1^{\circ} \mathrm{C}$ as a function of cross-stream coordinate and pressure. At the maximum measured pressure noted above, $a 0.1^{\circ} \mathrm{C}$ change in temperature gives nearly a $600 \mathrm{dbar}$ change in computed thermocline pressure, reflecting the weak vertical temperature gradients in the deep levels on the cold side of the Stream. The detailed spatial structure of the sensitivity in this range of pressures and cross-stream positions as shown in Fig. 11 is an artifact of extrapolating the model to temperatures less than $4.5^{\circ} \mathrm{C}$, so the model results associated with this extreme event must be interpreted with caution. High values of model sensitivity to measured temperature are also noted at shallow levels on the warm side of the Gulf Stream in conjunction with the weak vertical temperature gradients found there. 

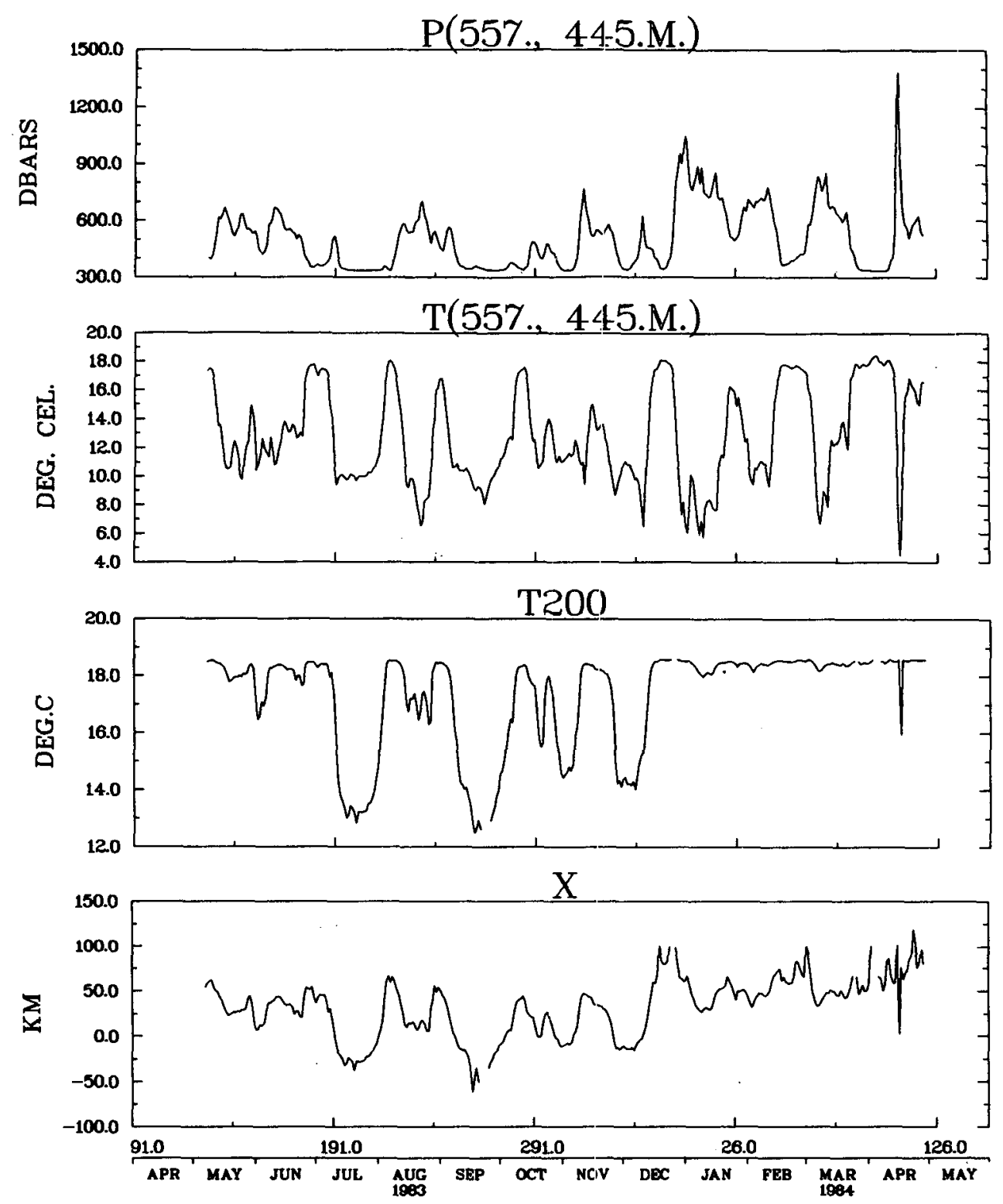

FIG. 10. Time series of daily averages of pressure and temperature from the nominal $500-\mathrm{m}$ level current meter on mooring 557 (upper two panels) and the associated model calculations of temperature at $200 \mathrm{dbar}$ $\left(\mathrm{T} 200\right.$, in $\left.{ }^{\circ} \mathrm{C}\right)$ and cross-stream coordinate $(X$, in $\mathrm{km})$ (lower two panels). Gaps in the model calculations reflect measured temperatures too warm or too cold at the measured pressure to be included in the range covered by the model, so that the mooring lies completely outside the Gulf Stream in the context of the model. The time axis is labeled by month and by sequential day number for 1983-84.

\section{Summary}

The main thermocline temperature field associated with the Gulf Stream as observed during a September 1983 survey near $59^{\circ} \mathrm{W}$ can be reproduced to an accuracy of a few tenths of a degree Celsius by means of simple analytical expressions and a limited number of empirical parameters. The model assumes a fixed crossstream spatial structure for the Gulf Stream and allows an interpretation of moored temperature measurements from a fixed mooring in terms of the time-de- pendent motion of this structure across the measurement site. The approach is obviously idealized and makes no allowance for likely time-dependent variations in the structure of the Gulf Stream such as may occur during meander and ring-formation events. The model does produce a useful tool for interpreting temperature records from a Gulf Stream mooring experiment which experienced mooring motions that were too large to be treated by any simple vertical interpolation scheme. It also provides a simple but reasonably realistic model of the observed structure of the Gulf 


\section{DC/DT (DBAR/O.1DEG.C)}

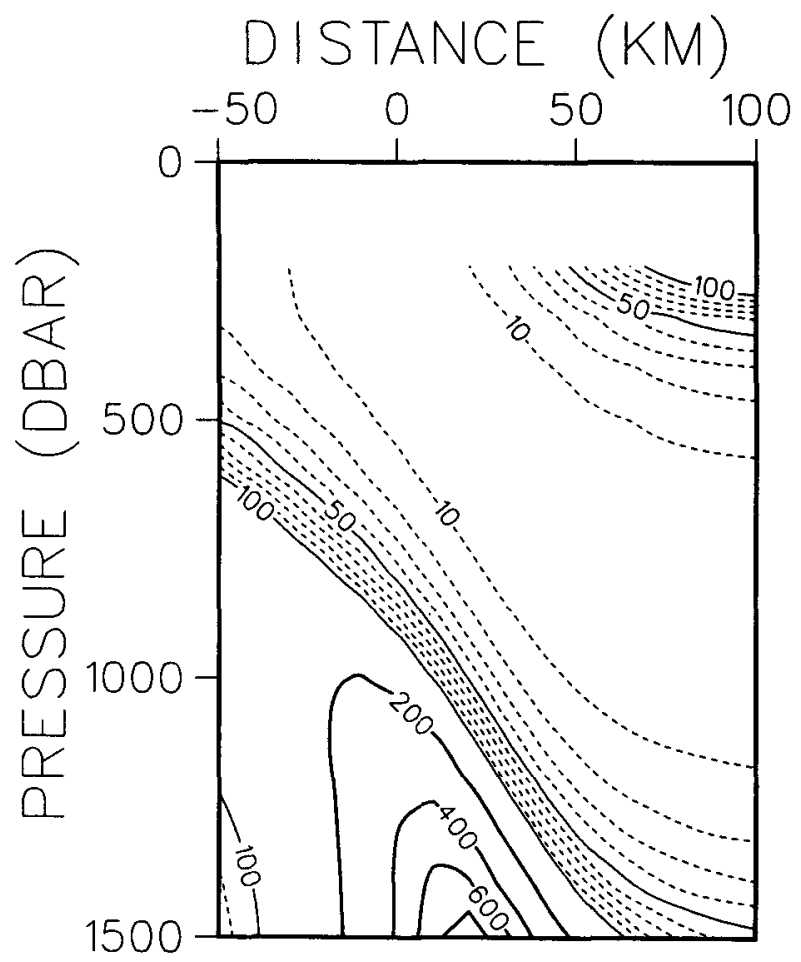

Fig. 11. Sensitivity of the model thermocline pressure (dbar) to a temperature change of $0.1^{\circ} \mathrm{C}$ as a function of pressure and crossstream coordinate. A central region showing changes of less than 10 dbar for a temperature change of $0.1^{\circ} \mathrm{C}$ mirrors the main thermocline, while higher sensitivities are observed at deep levels on the cold side of the model Gulf Stream and at shallow levels on the warm side where the vertical temperature gradients are relatively weak. The details of the model sensitivity at the deep levels on the cold side of the Stream are an artifact of extrapolating the model to temperatures less than $4.5^{\circ} \mathrm{C}$, the lower limit of the temperature range used in fitting the model parameters.

Stream of possible use for characterizing other Gulf Stream observations, for regional intercomparisons, or for initializing dynamical model studies.

\section{APPENDIX A}

\section{Details of the Parameter Fits}

Assuming a model temperature profile of the form

$$
T(p ; \mathrm{A}, \mathrm{B}, \mathrm{C}, \mathrm{D})=\mathrm{A} \tanh [\mathrm{B}(\mathrm{C}-p)]+\mathrm{D},
$$

best-fitting parameters $A, B, C$ and $D$ were selected using a nonlinear least-squares routine for each of 35 temperature profiles from CSS Dawson cruise 83-029. The fits were restricted to pressures and temperatures in the ranges 200 to $1500 \mathrm{dbar}$ and $4.5^{\circ}$ to $19^{\circ} \mathrm{C}$ respectively. An overall $\mathrm{rms}$ temperature residual of $0.16^{\circ} \mathrm{C}$ was achieved. Scatter plots of the resulting values of $A, B$, and $D$ against parameter $C$, and param- eter $\mathrm{D}$ against parameter $\mathrm{A}$, are shown in the main body of the text.

Parameter A (proportional to thermocline temperature step) is nearly constant for values of parameter $\mathrm{C}$ (thermocline pressure) greater than about $200 \mathrm{dbar}$, and increases with decreasing $C$ values less than 200 dbar. An exponential model of the form

$$
\mathrm{A}(\mathrm{C} ; \gamma, \delta, \epsilon)=\gamma \exp (-\delta \mathrm{C})+\epsilon
$$

was adopted and best-fitting parameters $\gamma, \delta$ and $\epsilon$ were selected using the nonlinear search routine on a subset of 30 of the paired values (A, C), with stations $1,6,8$, 15 and 16 having been excluded because one or more of the parameters fitted to these stations was judged to be anomalous compared to the generally observed trends. The temperature-salinity correlations for these stations (not shown) revealed the presence of fresher slope water intrusions, so there is some objective basis for the selection in addition to the subjective outlier criterion. The result was

$$
\begin{aligned}
\gamma & =8.92 & & {\left[{ }^{\circ} \mathrm{C}\right] } \\
\delta & =0.00912 & & {\left[\mathrm{dbar}^{-1}\right] } \\
\epsilon & =7.23 & & {\left[{ }^{\circ} \mathrm{C}\right] }
\end{aligned}
$$

with an rms residual in parameter $\mathrm{A}$ of $0.53^{\circ} \mathrm{C}$, compared to an initial standard deviation of approximately $1.6^{\circ} \mathrm{C}$ about a mean of $8.4^{\circ} \mathrm{C}$.

Parameter B (inversely proportional to the vertical scale of the thermocline) tends to a maximum at midrange $C$ values near $500 \mathrm{dbar}$ and decreases at lesser or greater thermocline pressures. A hyperbolic secant model of the form

$$
\mathrm{B}(\mathrm{C} ; a, b, c, d)=a \operatorname{sech}[b(\mathrm{C}-c)]+d
$$

was chosen and a similar least-squares fit of the 30 station subset gave

$$
\begin{aligned}
& a=2.65 \times 10^{-3} \quad\left[\mathrm{dbar}^{-1}\right] \\
& b=0.00251 \quad\left[\mathrm{dbar}^{-1}\right. \text { ] } \\
& c=557 \quad \text { [dbar] } \\
& d=0.98 \times 10^{-3} \quad\left[\mathrm{dbar}^{-1}\right]
\end{aligned}
$$

with an rms residual of $0.27 \times 10^{-3} \mathrm{dbar}^{-1}$. This can be compared to an initial standard deviation of 0.47 $\times 10^{-3} \mathrm{dbar}^{-1}$ about a mean of $3.2 \times 10^{-3} \mathrm{dbar}^{-1}$ for the 30 values of $B$ from the fits. As an aside, a Gaussian exponential function performed equally well in fitting the distribution of $B$ against $C$.

Parameter D (thermocline temperature) varies with thermocline pressure in much the same way as parameter A. Nearly constant values of $D$ of about $12^{\circ} \mathrm{C}$ are observed for $\mathrm{C}$ greater than $200 \mathrm{dbar}$, representing profiles with a middepth inflection point. For $\mathrm{C}<200$ dbar, parameter $D$ increases with decreasing $C$ in such a way that the 200 dbar temperature remains in the observed range of $12^{\circ}-13^{\circ} \mathrm{C}$ for stations near the inshore edge of the Stream. A three-parameter fit of D 
against $C$ of the same exponential form as (A2) left an $\mathrm{rms}$ residual in $\mathrm{D}$ of approximately $0.50^{\circ} \mathrm{C}$ for the 30 stations, compared with an initial standard deviation of approximately $1.6^{\circ} \mathrm{C}$ about a mean of $12.4^{\circ} \mathrm{C}$. An alternative two-parameter linear model for $\mathrm{D}$ versus $\mathrm{A}$ of the form

$$
\mathrm{D}(\mathrm{A})=\alpha \mathrm{A}+\beta
$$

was suggested by the correlation between $D$ and $A$ shown in the scatter plot in Fig. 9d. This linear predictor left an rms residual of only $0.18^{\circ} \mathrm{C}$ for the 30 stations. Equations (A2) and (A4) combine to give a composite fit of $D$ against $C$ with an rms residual of approximately $0.53^{\circ} \mathrm{C}$ and one fewer free parameter overall, and the composite model was the one adopted. The specific values of the parameters selected were

$$
\begin{aligned}
& \alpha=0.942 \\
& \beta=4.83 \quad\left[{ }^{\circ} \mathrm{C}\right] .
\end{aligned}
$$

The final model combines (A1)-(A4) to give a oneparameter family of temperature profiles $T(p ; \mathrm{C})$. Refitting the original 35 CTP stations with the composite model gave $C$ values ranging between 100 and 804 dbar and an overall rms temperature residual of $0.31^{\circ} \mathrm{C}$. A temperature residual of $0.21^{\circ} \mathrm{C}$ resulted if only the 30 station subset used in the parameter versus parameter fits was considered. This compares to overall rms temperature residuals in the four-parameter fits of approximately $0.16^{\circ} \mathrm{C}$ for either all 35 stations or the 30 station subset.

The composite model has a restricted domain of applicability in pressure-temperature space, reflecting the limits of the data over which the fits were computed and the specific functions used in the fits. For example, the temperature achieved by the model at any finite positive value of $\mathrm{C}$ is less than $(1+\alpha) \epsilon+\beta \approx 18.88^{\circ} \mathrm{C}$. For the specific model adopted, a unique relationship exists between thermocline pressure and temperature at fixed ambient pressures between 200 and $1500 \mathrm{dbar}$ over a central range of thermocline pressures from approximately 100 to 1000 dbar covering the cases of physical interest. The extremes of admissible $C$ values are defined by the vanishing of the partial derivative of model temperature with respect to thermocline pressure at a particular ambient pressure. For example, at the 200-dbar level this partial derivative vanishes at $\mathrm{C} \approx 100 \mathrm{dbar}, T \approx 12.4^{\circ} \mathrm{C}$ and at $\mathrm{C} \approx 1000 \mathrm{dbar}, T$ $\approx 18.6^{\circ} \mathrm{C}$. Thus, measured temperatures colder than $12.4^{\circ} \mathrm{C}$ or warmer than $18.6^{\circ} \mathrm{C}$ at 200 dbar are not accounted for by the model. Such conditions are considered to occur outside of the Gulf Stream proper as defined by the model, but they can be identified as either cold or warm outliers and assigned to the far field on either the landward or seaward side of the stream as appropriate.

Finally, each of the 35 fitted values of thermocline pressure was related to the cross-stream position of the corresponding CTP station $(x)$, defined as the minimum normal distance from the station to the $15^{\circ} \mathrm{C}$ isotherm at $200 \mathrm{dbar}$, using a fit of the form

$$
\mathrm{C}\left(x ; \mathrm{A}_{x}, \mathrm{~B}_{x}, \mathrm{C}_{x}, \mathrm{D}_{x}\right)=\mathrm{A}_{x} \tanh \left[\mathrm{B}_{x}\left(\mathrm{C}_{x}-x\right)\right]+\mathrm{D}_{x} \text {. }
$$

Equation (A5) implicitly defines the upper and lower limits of allowable thermocline pressures, with minimum $-A_{x}+D_{x}$ and maximum $A_{x}+D_{x}$. An unconstrained least-squares fit to all 35 cases gave

$$
\begin{array}{ll}
\mathrm{A}_{x}=322 & {[\mathrm{dbar}]} \\
\mathrm{B}_{x}=-0.0248 & {\left[\mathrm{~km}^{-1}\right]} \\
\mathrm{C}_{x}=10.6 & {[\mathrm{~km}]} \\
\mathrm{D}_{x}=445 & {[\mathrm{dbar}]}
\end{array}
$$

with an rms residual in thermocline pressure of 61.5 dbar. The original 35 values had a standard deviation of approximately $236 \mathrm{dbar}$ about a mean value of 438 dbar. This particular fit gave minimum and maximum thermocline pressures of 123 and $767 \mathrm{dbar}$, respectively. If the minimum and maximum thermocline pressures were fixed at 120 and $820 \mathrm{dbar}$, respectively, corresponding to $A_{x}=350 \mathrm{dbar}$ and $D_{x}=470 \mathrm{dbar}$, and the remaining two parameters were refit, slightly different values,

$$
\begin{array}{ll}
\mathrm{B}_{x}=-0.0215 & {\left[\mathrm{~km}^{-1}\right],} \\
\mathrm{C}_{x}=15.0 & {[\mathrm{~km}],}
\end{array}
$$

resulted. The new rms residual was $62.3 \mathrm{dbar}$, essentially unchanged. The constrained model has the advantage that it covers an expanded range of observed conditions characteristic of the warm side of the Gulf Stream. This model yields a thermocline pressure of approximately $361 \mathrm{dbar}$ at $x=0$ and a corresponding $200 \mathrm{dbar}$ temperature of $15.66^{\circ} \mathrm{C}$ instead of exactly $15^{\circ} \mathrm{C}$, since no special effort was made to preserve the origin of the coordinate system in either the free or constrained fits. If a further constraint was added to ensure that the fitted value of thermocline pressure at $x=\mathrm{C}$ gave a temperature of exactly $15^{\circ} \mathrm{C}$ at $200 \mathrm{dbar}$ $(\mathrm{C} \approx 323 \mathrm{dbar})$, the optimal values of the parameters in the fit changed slightly again to give

$$
\begin{array}{ll}
\mathrm{B}_{x}=-0.0243 & {\left[\mathrm{~km}^{-1}\right]} \\
\mathrm{C}_{x}=18.4 & {[\mathrm{~km}],}
\end{array}
$$

leaving an rms residual in thermocline pressure of 65.7 dbar. Any of these three fits are reasonably consistent with the actual measurements, and the last version was chosen for the calculations displayed in the body of the paper. The resulting horizontal scale $\mathrm{B}_{x}{ }^{-1} \approx 41$ $\mathrm{km}$ defines a half-width for the Gulf Stream. 


\section{APPENDIX B}

\section{Relationship of the Model to the Work of Hogg (1986)}

Hogg (1986) discusses a method for vertically extrapolating moored temperature measurements based on a quadratic regression of vertical temperature gradient against temperature of the form

$$
-d T / d p=\mathrm{a}_{0}+\mathrm{a}_{1} T+\mathrm{a}_{2} T^{2} .
$$

The integral, with respect to pressure, of (B1) gives a one-parameter family of hyperbolic tangent profiles of temperature versus pressure, with the free parameter corresponding to a pressure offset. Hogg (1986) corrects moored temperature readings to a fixed pressure level by choosing the particular member of this family which gives the measured temperature at the measured pressure. This corresponds to fixing parameters A, B and $D$ in (1) at some appropriate average value and allowing parameter $C$ to vary. The parametric model developed in the present paper extends this approach by providing a family of curves which approximate observed instantaneous temperature profiles, and a mechanism for selecting the appropriate member of the family for a particular measured pressure and temperature.

Expressions given by Hogg (1986) for WHOI mooring 776 located near the northern limits of the Gulf Stream and mooring 780 approximately $100 \mathrm{~km}$ west of mooring $\mathbf{5 5 7}$ were, respectively,

$$
\begin{aligned}
& -d T / d p=-0.0298+0.00847 T-3.17 \times 10^{-4} T^{2} \\
& -d T / d p=-0.0372+0.0104 T-4.43 \times 10^{-4} T^{2} .
\end{aligned}
$$

In the context of the model discussed in the present paper,

$$
-d T / d p=\mathrm{B}\left(\mathrm{A}^{2}-\mathrm{D}^{2}\right) / \mathrm{A}+(2 \mathrm{BD} / \mathrm{A}) T-(\mathrm{B} / \mathrm{A}) T^{2} .
$$

Equating (B1) and (B4), term by term, an equivalent thermocline pressure $\mathrm{C}$ for the two regressions can be calculated using

$$
\mathrm{D}=-\mathrm{a}_{1} / 2 \mathrm{a}_{2},
$$

(A2) and (A4). This gives $C=174$ dbar and $C=493$ dbar for moorings 776 and 780 , respectively. The corresponding values of $a_{0}$ computed from the model equations using these $C$ values are -0.0292 and -0.0412 , which agree to within about $10 \%$ with the values in (B2) and (B3) from Hogg (1986). The model assigns equivalent cross-stream positions of $-33 \mathrm{~km}$ and $21 \mathrm{~km}$ for moorings 776 and 780 , respectively. The regressions represent average conditions over the total measurement period, so these cross-stream positions are also an overall average in some sense. They are consistent with the geographic locations of the WHOI moorings with respect to the mean Gulf Stream, as shown in Fig. 1, if allowance is made for the spatial smearing of the meandering instantaneous Gulf Stream resulting in the time-averaged Gulf Stream whose approximate limits are shown in that figure.

\section{REFERENCES}

Auer, S. J., 1983: Gulf Stream surface landward edge statistics. NOAA Tech. Memo. NWS NMC 67, 20 pp.

Hendry, R. M., 1982: On the structure of the deep Gulf Stream. $J$. Mar. Res., 40, 119-142.

Hogg, N. G., 1986: On the correction of temperature and velocity time series for mooring motion. J. Atmos. Oceanic Technol., 3, 204-214.

- R. S. Pickart, R. M. Hendry and W. Smethie, Jr., 1986: On the northern recirculation gyre of the Gulf Stream. Deep-Sea Res., 33, 1139-1165.

Levy, E., and S. A. Tarbell, 1986: Moored current meter and temperature-pressure recorder measurements from the Western North Atlantic. High Energy Benthic Boundary Layer and Abyssal Circulation Experiments 1983-84. Vol. XXXIX, Woods Hole Oceanographic Institution Tech. Rep. WHOI-86-14, 40 pp. 